Ильин А. Н.

КУЛЬТУРА ПОТРЕБЛЕНИЯ КАК ФАКТОР ТРАНСФОРМАЦИИ СЕМЕЙНЫХ ЦЕННОСТЕЙ

Ильин А. Н.

A. N. Ilyin

КУЛЬТУРА ПОТРЕБЛЕНИЯ КАК ФАКТОР ТРАНСФОРМАЦИИ СЕМЕЙНЫХ ЦЕННОСТЕЙ

\title{
CULTURE OF CONSUMPTION AS A FACTOR OF FAMILY VALUES TRANSFORMATION
}

Ильин Алексей Николаевич - кандидат философских наук, доцент кафедры практической психологии Омского государственного педагогического университета (Россия, Омск); 644043, г. Омск, ул. Партизанская, 4a. E-mail: ilin1983@yandex.ru.

Mr. Alexey N. Ilyin - PhD in Philosophy, Professor, Practical Psychology Department, Omsk State pedagogical University (Russia, Omsk); 644043, Omsk, 4a Partizanskaja str. E-mail: ilin1983@yandex.ru.

Аннотация. В статье обосновывается оказание разрушительного влияния культуры потребления на семейные ценности. Абсолютизация комфорта, карьеры, материального достатка противоречит более высоким и духовным стремлениям. Связанный с культурой потребления индивидуализм и рождаемый ей феномен лёгкой социальности выступают в противовес солидарности и коллективизму. Социально значимые (в том числе семейные) ценности утрачивают своё распространение, оставляя место для индивидуально значимых ценностей.

Summary. This article argues that culture of consumption has had a devastating impact on family values. Absolute comfort, career, material wealth contradict with the higher and spiritual aspirations. Individualism, associated with the culture of consumption and the phenomenon of light sociality being its cause are opposed to collectivism and solidarity. Socially significant values (including family values) lose their spread, leaving space for individually significant values.

Ключевые слова: культура потребления, семья, лёгкая социальность, индивидуализм, гедонизм.

Key words: culture of consumption, family, light sociality, individualism, hedonism.

УДК 008 (103)

\section{Введение}

Духовность культуры, характерной для определённого народа и конкретного времени его существования, - тема настолько же актуальная, насколько однозначно не эксплицированная. В сегодняшней культуре российского общества существует весьма влиятельный культурный сегмент, который принято называть консюмеризмом. Культура потребления стала доминирующим культурным типом не только в России, но и во многих странах мира - глобализация делает своё дело, экспортируя ценности и нормы поведения из одного пространственного ареала в другой. Многие духовно-нравственные проблемы российского и мирового общества созданы или во многом усилены именно тенденцией к культурному крену в сторону консюмеризма. Потребительские ценности не являются «ценностями в себе», влияющими только на практики покупательского поведения, а оказывают глубокое деструктивное воздействие на различные формы сознания - политическое, нравственное, экологическое - и, соответственно, на политическое, нравственное, культурное, экологическое устройства социального бытия.

Культура потребления ценностно-смысловым ядром подразумевает символизм вещей, стимулирующий поведенческие практики демонстративной самопрезентации. Общество потребления общество имиджезации, где коммуникация осуществляется преимущественно актуализацией потребности в самопозиционировании. Символически насыщенный товар выступает стратифицирующим маркером, функция которого - осуществлять позиционирование потребителя.

Потребление - практика, имеющая мало общего с удовлетворением потребностей. Культура потребления формирует и закрепляет чёткую индивидуалистическую направленность, отвращает 


\section{Учёные записки}

сознание от серьёзных проблем современности и направляет его исключительно в сферу личного быта. Обладание модными брендовыми вещами как средствами выделения себя из общей массы становится значимым ценностным ядром, по сравнению с которым ценности солидаризма, коллективизма, патриотизма в значительной степени нейтрализуются. Потребкульт требует жить в роскоши и беззаботности, концентрировать своё внимание на перманентных покупках гаджетов и вещей, быстро выходящих из моды, требующей постоянно успевать за ней. Вследствие этого усиливается невнимание к другим людям, формируется феномен социальной безответственности и семейные ценности тоже уходят на второй план, представляясь в качестве слишком обременительных моральных обязательств.

Возникает явление лёгкой социальности, выраженной в поверхностности отношений. Она трансформирует восприятие других людей в функциональное, коммерческое и рыночное русло. Вместо душевности или, напротив, ненависти, возникают отчуждённость, равнодушие, поверхностность в отношениях, недоверие. Глубина отношений утрачивается, традиционные общественные связи разрываются, сами отношения формализуются и обезличиваются, одиночество выступает условием усиления потребительского поведения. Эмоциональность к социальной жизни, к другим снижается, и эту утрату компенсирует эмоциональная вовлечённость в частную жизнь.

Расширение сетевых связей в современном обществе во многом возникает благодаря распаду традиционных связей, которые характеризовались значительно большей прочностью. Согласно данным, одинокие люди тратят на одежду, продукты питания, лекарства, средства по уходу за собой, походы в рестораны и развлечения на 20-30 \% больше, чем семейные (возможно, в том числе поэтому пропаганда холостяцкого безответственного образа жизни так активна); в России на 6 человек семейных встречается 1 одинокий, а в столице одинок каждый третий [4]. Конечно, под ослаблением социальных связей далеко не всегда следует понимать одиночество. В основном имеется в виду переход к достаточно поверхностным отношениям. Общественному мнению, связанному с усиленным вниманием к предметам потребления, недалеко до полного пренебрежения интересами других, до крайней формы солипсизма.

Крупный город современного типа ослабляет социальную сплочённость в основном потому, что в нём исчезли многие прежние элементы городского пространства, по своей природе непотребительские или даже антипотребительские. Современные мегаполисы с их инфраструктурой отражают цель рыночной пользы, прибыли. Всё городское пространство наполнено потребительскими соблазнами, торговые площади и реклама стали неотъемлемой частью городского пейзажа и ликом глобальной капиталистической цивилизации. Они овладевают вниманием, призывают к избыточным покупкам, формируют ложные потребности. Инфраструктура и пространство нынешних городов, подстёгивая потребительские практики как способ самопрезентации, трансформируют ценностные ориентации, поведенческие практики и образ жизни общества и человека.

Если традиционные культуры, как правило, осуществляли сплочение людей, то потребительство актуализирует удовлетворение индивидуальных потребностей, что способствует эгоизации человека и разрушает межперсональное единство на разных уровнях - от семейных до конфессиональных, от малых групп до больших.

Даже любовь становится на некий имиджевый поток, переставая быть самой собой. Лёгкие отношения, стремление пожертвовать глубиной связей во имя нарастания их количества, секс без обязательств входят в жизнь современного общества. Коллекционирование сексуальных связей с различными партнёрами представляется консюмеру чем-то вроде коллекционирования вещей. Секс отделяется от чувственной сферы (любовь), институционально-духовной сферы (семья), лично-духовной сферы (ответственность). Скоротечный акт, даже если он повторяется какое-то время с одним и тем же партнёром, не ограничивает свободы в дальнейшем выбирать себе партнёров, ибо количество партнеров - знак собственного престижа. В ином случае потребитель заинтересован в односторонней любви - в желании быть любимым, но не любить. Как заметил Э. Фромм, стараясь вызвать чувство к себе со стороны других, человек стремится к максимальному материальному успеху (деньги, престиж, власть) и у него не хватает времени на подлинную любовь, на искусство любить [17]. Однако «многочисленность связей не может заменить 
Ильин А. Н.

КУЛЬТУРА ПОТРЕБЛЕНИЯ КАК ФАКТОР ТРАНСФОРМАЦИИ СЕМЕЙНЫХ ЦЕННОСТЕЙ

тождествообразующую силу стабильных первичных взаимоотношений» $[1,172]$.

Задаётся вполне обоснованным вопросом С. Жижек: «...что, если в нашем постмодернистском мире предписываемой трансгрессии, где супружеская верность воспринимается как старорежимное чудачество, по-настоящему подрывным оказывается поведение тех, кто цепляется за неё? Что, если искренняя свадьба сегодня есть “самая тайная и смелая из всех трансгрессий?”» [7, 111]. Б. Райнов, ещё в 70-е гг. ХХ в. описывая последствия сексуальной революции на Западе, отмечал увеличение случаев сексуальных преступлений, показное презрение молодёжи к чувству любви как старомодной сентиментальности, которая является признаком отсталости и слабости [14]. Все эти явления характерны и для современного российского общества, в котором инфраструктура потребления чрезвычайно сексуализирована, а благодаря в том числе и ей, - весь быт. К счастью, «идеология интимности» перечисленными Райновым явлениями не ограничивается, и, естественно, остаётся немало места для их противоположности - для «архаичных» традиционных ценностей любви, преданности, духовности. Только сами по себе потребительские ценностные ориентиры противоречат укоренённости в возвышенном чувстве любви и культивируют разврат, сексуальную «новизну», антисемейственность, «любовную независимость» и т. д. То, что называется сексуальной демократизацией, по существу превратилось в примитивизацию и коммерциализацию интимности, в снижение «градуса» духовности и романтизма. Здесь уместно привести слова Э. Гидденса, произнесённые в несколько ином контексте: «...сексуальность является не антитезой цивилизации, посвятившей себя экономическому росту и техническому контролю, а воплощением её неудачи» [3, 208].

Тут важно обратить внимание на демографический аспект проблемы, а именно на то, что потребительство и связанный с ним гедонизм способствуют сокращению уровня рождаемости. Консюмеризм вместо семейных ценностей придерживается индивидуализма, согласно которому жить надо в кайф и для себя, а не для семьи или детей. Потребительство как таковое направлено в сторону карьеризма, культа личной успешности, что идёт вразрез со стремлением обзавестись семьей и детьми. Множащиеся организации типа Child free («Свобода от детей») только культивируют идеологию потребительского индивидуализма, убеждая, что дети - это ненужная обуза. И даже в странах с высоким уровнем дохода населения, но в которых господствуют потребительские ценности, наблюдается демографический спад, поскольку потребительская культура делает своё дело, в том числе и там, где у людей есть материальная возможность обеспечивать детей. Ссылаясь на книгу П. Бьюкенена, В. Г. Федотова пишет, что на Западе индекс рождаемости составляет 1,4, когда для воспроизводства населения нужно 2,25 [16]. Как мудро заметил М. Делягин, вызванное потребительской ориентацией сокращение численности населения в развитых странах свидетельствует о глубоком внутреннем неблагополучии обществ [6].

Недаром отмечается, что по социально-демографическим характеристикам транжирышоперы, вкладывающие огромные деньги в брендовый символизм, - обычно неженатые/незамужние молодые люди или молодые семейные пары без детей [5]. Малодетность не обязательно связана с повышенным уровнем смертности или низким уровнем благосостояния. Поэтому стоит отчасти согласиться с утверждением А. Никонова о том, что если в прежние века регулятором рождаемости были эпидемии чумы и других болезней, то сегодня этим регулятором выступает приобретённый за счёт развития техники и технологий комфорт, который декларирует жизнь для себя, а не для своих детей. Ранее зрелость и самостоятельность наступала годам к 16 , а сегодня она и в 30 может не наступить, что объясняется не только потребительскими тенденциями, но и спецификой информационной цивилизации, в которой от каждого специалиста требуется постоянно обновлять свои знания для того, чтобы идти параллельно развитию технологий; постоянно обучаясь, он испытывает дефицит времени на семью и многое другое. Так что закономерна демографическая стабилизация, выраженная в нулевом приросте, именно для развитых стран, наполненных комфортом [13]. Не согласимся только в положительной оценке данных тенденций, высказываемой Никоновым.

Сегодня в среде молодёжи слабеет желание обзаводиться семьёй; браки отличаются запоздалостью и неустойчивостью, уровень рождаемости снижается. Бытовавшее в прошлом возвы- 
шенное отношение к семье уступает место представленности семьи как необременительного сожительства. «Антисемейная идеология «живёт и побеждает» потому, что предлагаемый ею идеологический товар легко усваивается на животно-инстинктивном уровне и в первую очередь ориентирован на «обжорливую младость», познающую мир через наушники плееров, экраны телевизоров и мониторы подключённых к Интернету компьютеров» $[11,30]$. В качестве источников этой идеологии В. Н. Лексин правомерно выдвигает следующие: 1) концепция угрозы перенаселения и увеличения количества неполноценных людей (теория и практика «планирования семьи»); 2) трактовка брака как несвободы и противопоставление ему свободной любви как формы отсутствия семейных обязательств; 3) либерально-рыночные интерпретации брака не как сакральной духовной ценности, а как партнёрских отношений. Антисемейная идеология выступает чуть ли не манифестом, указывающим путь к отказу от нежелательного, психологически и финансово затратного родительства, которому противопоставляется индивидуальное благополучие и гедонистическая жизнь, лишённая обузы.

Кстати, последний пункт весьма интересен тем, что рыночная идеология проникает именно туда, где ей места вообще нет и быть не должно. Согласно ей, отношения между мужем, женой и детьми призваны носить монетарный характер (один из примеров - брачный контракт), они должны платить друг другу деньги, например, за помощь по хозяйству и т. д. В книге «Девиантность в обществе потребления» находим несколько примеров - выдержек из проекта договора между супругами (из практики петербургского суда):

«Муж обязан предложить жене поговорить с ней каждый день с 20:30 в течение часа. Если он забыл или сделал вид, что забыл, он уплачивает штраф...».

«В случае измены жена уплачивает штраф в размере 1/3 стоимости квартиры, начиная со второй измены...».

«Супруг уплачивает штраф за попытку оставить другого супруга наедине со своими родственниками. Список лиц, которых нельзя пускать в дом без согласия второго супруга, указывается в качестве неотъемлемой части настоящего договора».

«Жена обязана предупредить мужа о своём эмоциональном состоянии не менее чем за две недели с тем, чтобы он успел выработать контраргументы» ${ }^{1}$.

При реализации монетаризма в семье последняя перестаёт быть семьёй. В мире не всё продаётся и покупается, как бы там ни считали отчаянные рыночники. Есть явления, возникающие по ту сторону рынка. К ним прежде всего относятся любовь и патриотизм. Доведённая до крайности рыночная идеология предполагает дозволенность торговать политическими партиями (кстати, это довольно широко себя проявляет), убеждениями, отношениями, Отечеством, детьми. Эта идеология - тотальный инструмент десакрализации всего.

Ячейкой общества всегда являлась семья, но теперь, с постепенной утратой социальности, её легитимность ставится под сомнение несмотря на то, что лишь семья способна быть общественной ячейкой; один человек, в отличие от семьи, не может продолжать род, а потому необходим социальный скреп в виде семьи. К тому же семья - это особый социальный мир, позволяющий скрыться от проблем повседневности, решить их всеобщими усилиями членов семьи, мир заботы, уюта, человеческого тепла и любви. Ребёнок развивается семьёй и в семье, которая даёт ему любовь, заботу, понимание. Именно в семье происходит первичная социализация, обеспечивается преемственность языка, трудовых навыков, этических представлений. Именно в семье ребенок получает первоначальные и определяющие понятия о добре и зле, формирует модели поведения и нормы общения, наконец, посредством семейного воспитания формируется как личность. «...Многие институты человеческой жизни, будь то устоявшийся круг дружеского общения, будь то приход, монашеская или дружеская община, добровольное творческое объединение, иной раз даже - в некотором идеальном случае - трудовой коллектив или воинское подразделение, обретают свою прочность и благоприятный человеческий климат именно благодаря тем навыкам друже-

${ }^{1}$ Девиантность в обществе потребления: Коллективная монография. Под ред. Я. И. Гилинского и Т. В. Шипуновой. - СПб.: Издательский Дом «Алеф-Пресс», 2012. - 464 с., с. 163. 
Ильин А. Н.

КУЛЬТУРА ПОТРЕБЛЕНИЯ КАК ФАКТОР ТРАНСФОРМАЦИИ СЕМЕЙНЫХ ЦЕННОСТЕЙ

ского общения, заботы и взаимной ответственности, которые слагаются именно в семье. Слагаются - вопреки всем возможным злоупотреблениям внутрисемейным авторитетом или тем внутрисемейным распрям, описания которых с древнейших времён стали неотъемлемой частью и мифологии, и литературы, и историографии» ${ }^{2}$. Без семьи, без традиционного семейного воспитания не просто вырастает неповзрослевший, инфантильный человек, но и не формируется личность как таковая.

На Западе с его развитой потребительской индустрией (и, соответственно, потребительской культурой) либеральный индивидуализм диктует правило, согласно которому ячейка общества индивид. Вместо утверждения интересов и прав семьи как коллектива любящих друг друга людей утверждаются права ребенка, которые, к тому же, противопоставляются правам родителей; вспомним ювенальную юстицию, которая под видом борьбы с внутрисемейным насилием над детьми легитимирует детскую вседозволенность и наносит сокрушительный удар по институту семьи.

Приведём цитату из книги Ж. Липовецки: «Кто ещё может верить в труд, узнав о масштабах прогулов и turn over (текучесть рабочей силы), о страсти к отпускам, уик-эндам, развлечениям, которая не перестаёт усиливаться, когда уход на пенсию становится всеобщим стремлением, если не идеалом жизни; кто ещё может верить в семью, когда число разводов неуклонно увеличивается, когда стариков загоняют в дома престарелых, когда пожилые желают оставаться «молодыми» и участвуют в конкурсах «пси»; когда супружеские пары становятся «свободными», когда узаконены аборты, применение контрацептивов; кто ещё может думать об армии, когда принимаются все меры для того, чтобы её реформировать, когда уклонение от военной службы уже не считается бесчестием; можно ли говорить о добросовестности, экономии, о профессиональной этике, об авторитете, о санкциях?» [12, 58-59].

В прошлые века дети считались сакральным даром, подарком судьбы. Бездетные поэтому чувствовали себя неполноценными. Существовали различные поговорки на эту тематику, например: «Бездетный умрёт, и собака не взвоет», «Живёшь - не с кем покалякать», «Семья без детей что цветок без запаха», «Дом с детьми - базар, дом без детей - могила» и т. д. (см. [15]). Если ранее молодые люди видели смысл жизни в своих детях, теперь они детей расценивают как барьер для реализации смысла жизни, сводимого преимущественно к развлечениям. Если ранее в СМИ культивировался идеальный образ женщины как матери, а мужчины - как отца, теперь идеальным образом обоих становится бесполый консюмер. Мир культуры подавил многие социально вредные проявления человека, а мир потребительской культуры подавляет инстинкт воспроизводства жизни, подменяя его искусственно сконструированным «инстинктом гедонизма». Чем больший выбор предоставляет цивилизация для различных жизненных практик, тем в меньшей степени брак и рождение детей рассматриваются как сакральные ценности. Потребкульт и вся потребительская инфраструктура предлагают множество форм деятельности (прежде всего развлекательной), не связанных с семейной жизнью и деторождением. Потребительская инфраструктура максимально развита в городах. В том числе по этой причине именно в городской среде, в отличие от сельской, наблюдается наибольшее количество бездетных женщин; в городской среде рождение ребёнка часто откладывается и, соответственно, средний возраст женщины, рожающей первого ребенка, повышается. Личные благоденствие и комфорт абсолютизируются как высшие ценности, но за них предлагается платить бездетностью.

Консюмеристскому влиянию оказались подвержены едва ли не все социальные группы российского общества, но особенно молодёжь, становление которой проходило на фоне рыночных изменений российской экономики и формирования новых ценностей. Сегодня всё менее наблюдается позитивная консолидация молодёжи, основанная на солидарности, сотрудничестве и руководстве общественно-полезными целями. А вот негативная консолидация (криминальность) в постперестроечное время начала стремительно развиваться. «Положительные» объединения требуют от инициаторов проявить больше усилий, чем «отрицательные»; последним значительно

2 Рашковский Е. Б. Феномен семьи (междисциплинарные заметки) // Вопросы философии. - 2010. - № 10, c. $27-37$, c. 28 . 


\section{Учёные записки}

Комсомольского-на-Амуре государственного технического университета

легче возникнуть. В настоящее время существует, конечно, много молодёжных объединений, но основным мотивом вступления в них является не желание быть полезным обществу, а стремление всё к той же карьере; объединения, с помощью которых осуществляется позитивная консолидация, чаще всего рассматриваются в качестве социального лифта. Процессы молодёжной самоорганизации либо имитируются, либо навязываются извне.

После катастрофических для народа либеральных реформ возникла ужасающая бедность на фоне демонстративного богатства немногих и роскоши выставленных витрин. В результате не только распространения потребительских ценностей как таковых, но и либеральных реформ (вследствие которых потребкульт укоренился), снизивших уровень жизни и изменивших систему ценностей, возникло явление социального распада, деконсолидации и деполитизации. «По нашему народу прошли трещины и разломы. Люди съёжились, сплотились семьями и маленькими группами, отдаляются друг от друга, как разбегаются атомы газа в пустоте. Народ, который в недавнем прошлом был цельным и единым, становится похож на кучу песка. Но сначала его раскололи на большие блоки - и так умело, что мелкие трещины прошли по всем частям» [9]. Прежние ценности коллективизма, солидаризма, сопричастности общему делу, труда ради благой социальной, а не индивидуальной цели потеряли свою значимость. Как заметил В. В. Кривошеев, «ныне общество всё больше воспринимается индивидами как поле битвы за сугубо личные интересы, при этом в значительной мере оказались деформированными пусть порой и непрочные механизмы сопряжения интересов разного уровня. Переход к такому атомизированному обществу и определил своеобразие его аномии» [8].

Статистику депопуляции в странах Запада приводит и делает прогноз о возможном вырождении Запада П. Бьюкенен. Он обоснованно пишет, что на падение уровня рождаемости оказывают влияние потребительский гедонизм, индивидуализм, феминизм, насаждение толерантности, карьеризм, дехристианизация [2]. В качестве одной из причин снижения уровня рождаемости он называет социалистическую гарантию пенсии. Когда есть пенсия и связанная с ней экономическая независимость, нивелируется потребность в семье и детях. Какое мы видим «замечательное» оправдание либеральных антиобщественных реформ: «нам пенсии не нужны, так как они мешают воспроизводству». Пенсии - не пережиток проклятого социализма, поэтому связывание их с социалистическим режимом - верх лицемерия. В капиталистических странах того же Запада, в эпоху welfare state, пенсионное обеспечение было обязательным. И явно не оно - главная причина депопуляции. Волна индивидуализма, гедонизация и реформы типа ювенальных - намного более значимые причины снижения уровня рождаемости. Правда, о ювенальной юстиции Бьюкенен предпочитает умолчать и не упоминает о ней вовсе.

В депопуляции на Западе Бьюкенен обвиняет в том числе неомарксистов типа представителей Франкфуртской школы, которые подрывали семейные ценности и рассматривали семью как буржуазный пережиток. Вообще, согласно Бьюкенену, культурную революцию по подрыву традиционных ценностей в самом широком смысле, осуществляли неомарксисты. Однако следует высказать несколько возражений. Далеко не весь Запад зачитывался творенинями Д. Лукача, А. Грамши, М. Хоркхаймера, Т. Адорно, Э. Фромма, Г. Маркузе. Их работы были достоянием в основном только интеллектуалов и потому не могли повлиять и постоянно поддерживать это влияние на массовое сознание, перестраивая последнее под свой идеал. Да, труды франкфуртцев оказывали влияние, но лишь на американскую молодёжь 60-х гг. ХХ в. В последующие десятилетия эти философы (как и философия в целом) в деле формирования массового сознания принимали участие менее активное, чем вполне буржуазные СМИ. Смешно даже предполагать, что трактат Адорно более популярен в массах, чем какое-либо ток-шоу. Тем более сам Бьюкенен пишет, что немногие знали франкфуртцев по именам. Антисемейные ценности проповедуются не только марксистами (и то лишь некоторыми), но и современными либеральными идеологами, которые являются убеждёнными антимарксистами. Антисемейными ценностями полнится культура потребительского гедонизма, которую неомарксистские теоретики подвергают жёсткой критике вспомним хотя бы «Одномерного человека» Г. Маркузе, а также Т. Адорно и М. Хоркхаймера, изобличавших в своей «Диалектике просвещения» потребительскую капиталистическую культуриндустрию. 
Ильин А. Н.

КУЛЬТУРА ПОТРЕБЛЕНИЯ КАК ФАКТОР ТРАНСФОРМАЦИИ СЕМЕЙНЫХ ЦЕННОСТЕЙ

Никакая горстка марксистов-ревизионистов в принципе не смогла преобразовать европейскую и американскую культуры - да ещё в сторону совсем антимарксистского консюмеризма. Вряд ли кто-либо из франкфуртцев хотел увидеть Запад будущего таким гедонистическим и индивидуалистическим, каким он стал. И пусть Бьюкенен покажет пальцем на кого-то из этих мыслителей, кто воспевал потребительские ценности и характерную для современного Запада политкорректность. Но указывать не на кого. Кроме того, при чём тут марксизм, если в США и Европе крайне низка доля пропаганды классовой борьбы, выравнивания доходов, декоммерциализации медицины и образования? Там нет сильной коммунистической партии. Зато повально распространена насаждаемая сверху идеология свободного рынка, равенства возможностей и прочих типично либерально-капиталистических ценностей.

Очевидно, что Бьюкенен занимается «ложной критикой», подтасовывая факты и выстраивая схемы, обличающие невиновных и обходящие стороной виновных. Обвинять марксизм в инициированных либеральным капитализмом злодеяниях - значит сваливать с больной головы на здоровую. Видимо, просто всё плохое ассоциируется с «гнусными коммунистами» - в лучших традициях капиталистической идеологически насыщенной мысли. Осталось только коммунистов и социалистов обвинить в росте имущественного расслоения, происходящего как внутри Запада, так и между странами, в экономическом закабалении Западом других стран, в росте влияния транснациональных корпораций на национальные правительства. Думаю, подобный абсурд мы скоро найдём в интеллектуальном мусоре а-ля Бьюкенен или а-ля Фукуяма.

Противные Бьюкенену повальный консюмеризм, дехристианизация, гомофилия, бунт против вполне здоровой гомофобии, ценности child free, антипатриотизм, противоречащая здравому смыслу толерастия - все это детища не марксизма, не контркультурной идеологии «детей цветов», $\mathrm{a}$, напротив, либерального капиталистического идеологизма. Из слов великого коммунистического идеолога о том, что пролетариат не имеет отечества, вовсе не следует, будто любые проявления антипатриотизма исходят от марксистской мысли. Из высказываемых некоторыми теоретиками коммунизма суждениями о семье как пережитке буржуазного общества нельзя заключать, что всякий бунт против семьи - отпрыск коммунистов. В общем, поход Бьюкенена против марксизма имеет под собой мифологическую основу.

Один из немногих положительных аспектов деятельности правительства - введение доплаты за рождение второго ребенка, так называемый материнский капитал. Понятно, что эти деньги не слишком повышают покупательскую способность людей и вряд ли они являются серьёзным стимулом для рождения детей. К тому же их нельзя потратить на самые насущные нужды вроде питания и лечения. Но всё же их наличие намного лучше, чем отсутствие. К сожалению, эта мера не имеет достаточного веса при решении проблемы рождаемости, да и не компенсирует суммарные родительские затраты на ясли и детские сады, детскую одежду, питание, учебники, образование, медицинское обслуживание, отдых. Всё это сегодня находится в труднодоступной зоне. К тому же беспредельно высокие цены на квартиры и кабальная ипотека очень сильно бьют по семьям, особенно молодым, которые сталкиваются с проблемой отсутствия жилья. Поэтому, не умаляя необходимости материнского капитала, отмечу, что рекламные фразы «слуг народа» о материнском капитале как серьёзном прогрессе по сравнению с советским периодом не оправданы. В СССР не было введено такой доплаты, но и затраты на вышеперечисленные детские нужды были значительно ниже. Человек чувствовал уверенность в завтрашнем дне и потому имел мотивацию к рождению детей. В то время отсутствовала «антисемейная» потребительская пропаганда, представляющая семью как рудимент и ставящая на её место карьеру и удовольствия. Вот только партийные агитаторы это не учитывают в своей пропаганде, выпячивая однобокое видение проблемы, точнее, не проблемы, а достижения, о котором в стране советов даже не помышляли.

\section{Заключение}

Для повышения уровня рождаемости в стране необходимо принять множество мер различного характера и степени сложности. Важно объявить борьбу против потребительских идеологических тенденций, которые воспевают жизнь для себя любимого, представляют детей в качестве ненужной обузы и отвращают от обзаведения потомством; ведь нарушено не только количествен- 


\section{Учёные записки}

Комсомольского-на-Амуре государственного технического университета

ное (демографическое) воспроизводство, но и качественное (культурное). В частности, необходимо ограничить поле деятельности коммерческой рекламы - манипулирующей сознанием, акцентирующей внимание лишь на вещизме, предлагающей «жить в кайф». Телеэфир должны заполнять не люди неидентифицируемого пола, пропагандирующие вещизм, индивидуализм, бездетность, рассматривающие детей как тяжкую ношу и говорящие о вреде семейной жизни для свободы и возможностей покупать новые модные сотовые телефоны и одежду от кутюр. Пусть медиаэфир наполняют люди, вещающие о счастье в семейной жизни и воспитании детей. Пусть это будут беременные женщины и многодетные матери, которые своим примером учат реципиентов. Массмедиа всегда пропагандируют и внушают, и от этого никуда не деться. Следует внушать действительно значимые ценности, а не потребительский китч, разлагающий общество и деморализующий человека. Только эти ценности необходимо внушать интересными способами, а не путём нудного морализаторства, как это делалось в советский период.

Однако пропагандой деторождения дело не должно ограничиваться, иначе она станет пиком лицемерия в стране, где экономические условия действительно превращают детей в тяжесть. В целом для улучшения демографической ситуации требуется отход от экономического либерализма, то есть значительная социализация.

Нельзя ожидать высокого уровня рождаемости, если, по данным С. Кара-Мурзы, в 2003 году даже в Москве 50 \% опрошенных первой жизненной проблемой назвали страх за своё будущее и будущее своих детей, а в Северной Осетии такой страх представили как первую проблему 60 \% [10]. Лишь увеличением доплат побороть этот страх не получится. Необходимо бросить все силы на повышение уровня народного благосостояния, снижение безработицы и обеспечение уверенности в завтрашнем дне. Ведь отсутствие как достойного благосостояния, так и уверенности в будущем выступают важными демотивирующими факторами в контексте обзаведения детьми. Одним из аспектов борьбы с нищетой является обеспечение достаточного прожиточного минимума. Имеет смысл выплачивать пособие, которого хватает на нормальный уход за ребёнком. Важно качественно повысить доплаты за рождение детей. Нужно обеспечить большое количество бесплатных мест в детских дошкольных и школьных учреждениях, сделать обучение, воспитание и здравоохранение финансово доступными.

Обязательно следует упростить сбор бесконечных справок на получение детского пособия, на получение места в яслях или детском саду. Необходимо создать условия, при которых связанные с рождением детей перерывы в профессиональной деятельности женщин не повлияют негативно на их материальный достаток; тогда пойдёт на убыль уровень отвлечённости женщин от семьи в пользу карьеры, а также снизится возраст для материнства (сегодня он растёт).

Изменения в медийно-культурной сфере, а также действительная национальноориентированная экономическая политика, связанная с модернизацией инфраструктуры и созданием рабочих мест, вернут молодым людям уверенность в будущем и смысл жизни. Но перечисленное невозможно реализовать в русле социально безответственной либеральной политики, проведение которой в России выгодно не нашему народу, а нашим геополитическим конкурентам и сращённому с ними транснациональному капиталу. Либерализм предполагает отказ от протекционизма и открытие экономики страны, повальную приватизацию, проникновение монетаризма во все сферы жизни, коммерциализацию культуры, сворачивание социальной политики, дарование людям свободы от государственной заботы. Это всё несовместимо ни с демографическим ростом, ни с борьбой против потребительской культуры, ни с повышением народного благосостояния, ни с экономическим развитием, ни с жизнью страны в целом. А если взглянуть на проблему шире и увидеть в политическом курсе не только либеральную, но и коррупционную составляющую, приходится констатировать ещё большую несовместимость этого курса с жизненно важными интересами народа и страны.

Решения о рождении детей люди принимают под воздействием самых разных аспектов реальности, и меры как экономической, так и культурной политики - всего лишь одни из таких аспектов. Сама же депопуляция - не первопричина кризисов и проблем, а скорее ответ людей на серьёзные проблемы, с которыми они столкнулись. 


\section{ЛИТЕРАТУРА}

1. Бек, У. Общество риска. На пути к другому модерну / У. Бек. - М.: Прогресс-Традиция, 2000. - 384 с.

2. Бьюкенен, П. Дж. Смерть Запада / П. Дж. Бьюкенен. - М.: АСТ, 2003. - 444 с.

3. Гидденс, Э. Трансформация интимности / Э. Гидденс. - СПб.: Питер, 2004. - 208 с.

4. Голова, А. Г. Факторы, влияющие на потребительское поведение личности в мегаполисе / А. Г. Голова // Журнал социологии и социальной антропологии. - 2011. - Т. XIV. - № 5(58). - С. 304-312.

5. Гурова, О. Ю. Шопинг, одежда и типология потребителей в Санкт-Петербурге / О. Ю. Гурова // Журнал социологии и социальной антропологии. - 2011. - T. XIV. - № 5(58). - С. 129-141.

6. Делягин, М. Возмездие на пороге. Революция в России: когда, как, зачем / М. Делягин. - М.: Новости, 2007. $-446 \mathrm{c}$.

7. Жижек, С. Накануне Господина: сотрясая рамки / С. Жижек. - М.: Европа, 2014. - 280 с.

8. Кара-Мурза, С. Аномия: особенности российской болезни [Электронный ресурс] / С. Кара-Мурза // Россия навсегда. Народные ведомости. - Режим доступа: http://rossiyanavsegda.ru/read/554/.

9. Кара-Мурза, С. Аномия бедности [Электронный ресурс] / С. Кара-Мурза // Россия навсегда. Народные ведомости. - Режим доступа: http://rossiyanavsegda.ru/read/617/.

10. Кара-Мурза, С. Г. Угрозы России. Точка невозврата / С. Г. Кара-Мурза. - М.: Эксмо: Алгоритм, 2012. $592 \mathrm{c}$.

11. Лексин, В. Н. Идеологические основы упадка современного института семьи / В. Н. Лексин // Общественные науки и современность. - 2011. - № 2. - С. 29-42.

12. Липовецки, Ж. Эра пустоты / Ж. Липовецки. - СПб.: Изд-во «Владимир Даль», 2001. - 332 с.

13. Никонов, А. П. Апгрейд обезьяны. Большая история маленькой сингулярности / А. П. Никонов. - М.: Изд-во НЦ ЭНАС, 2005. - 352 с.

14. Райнов, Б. Массовая культура / Б. Райнов. - М.: Прогресс, 1979. - 490 с.

15. Фахрисламова, Р. Т. Феномен женской бездетности в России: исторические и социальные предпосылки / Р. Т. Фахрисламова // Социологический журнал. - 2014. - № 3. - С. 33-54.

16. Федотова, В. Г. Факторы ценностных изменений на Западе и в России / В. Г. Федотова // Вопросы философии. - 2005. - № 11. - С. 3-23.

17. Фромм, Э. Искусство любить: Исследование природы любви / Э. Фромм. - М.: Педагогика, 1990. $160 \mathrm{c}$. 